\title{
The Nexus between Inflation Risk and Consumer Perception
}

\author{
Kai Shi \\ School of Economics \\ Northeast Normal University \\ Changchun, P. R. China \\ E-mail: shik142@nenu.edu.cn
}

\author{
Yuan Wang \\ School of Economics \\ Northeast Normal University \\ Changchun, P. R. China \\ E-mail: 1206898080@qq.com
}

\author{
Li Nie \\ Graduate School of Commerce and Management \\ Administration \\ Hitotsubashi University \\ Tokyo, Japan \\ E-mail: brilliant.so.kai@gmail.com
}

\begin{abstract}
This article discusses the relation between the risk of price instability and consumer perception. After quantifying the inflation/deflation risk, which introduces the preference of economic representatives as well as the whole probability distribution of price level deviating from the target zone, based on GARCH model and bootstrapping, we employ a stepwise least square to investigate the nexus between balance of risk and consumer perception. Although empirical results only find relatively weak connection between these two factors, the methodology opens a new window for future quantitative analyses.
\end{abstract}

Keywords—inflation risk; consumer perception; GARCH; bootstrapping

\section{INTRODUCTION}

How does inflation risk influence consumer perception? Does higher inflation risk cut down consumers' happiness? All these answers which rely on quantifying inflation risk contribute to the literature on inflation. Quantifying inflation risk is a relatively new research area. From the perspective of risk definition, any risk measurement tools must possess two basic requirements: one is that it must be linked to the probability distribution of random variables, and the other is that it should reflect the preference of economic representatives (Machina and Rothschild, 1987). [1] Based on this, Kilian and Manganelli (2007) creatively proposed the methodology of quantifying inflation risk based on GARCH model and bootstrapping. [2] This approach provides a truly valuable risk measurement mode in accord with the essence of risk definition and open a new era of empirical research based on inflation risk. In this article, we try to explore the nexus between inflation risk and consumer perception.

\section{MEASUREMENT OF INFLATION RISK}

First of all, in order to quantify price instability risk it is necessary to define price stability. The "price stability" mentioned in this article does not only refer to the stability of price level but also keep in line with policy makers' so called "price stability", which basically equals to the definition of low inflation.

Let $[\pi, \pi]$ represents the region of price stability: when real inflation rate stays in this region, price level keeps stable whereas either real inflation rate are higher than the upper bound $\pi>\pi$ or lower than the lower bound $\pi<\pi$ means "price instability", inflation or deflation. Thus inflation or deflation risk essentially relates to the deviation of real inflation rate from the price stability region. Both of the two risks rely on the probability distribution $\mathrm{F}$, the determination of price stability region and different preferences of economic representatives for inflation and deflation. Any inflation risk measurement must take the three aspects into account at the same time.

As for the preference of economic representatives, it can be expressed as such following function of real inflation,

$$
l(\pi)=\left\{\begin{array}{cc}
\varphi(\underline{\pi}-\pi)^{\alpha} & \pi<\underline{\pi} \\
0 & \underline{\pi} \leq \pi \leq \bar{\pi} \\
(1-\varphi)(\pi-\bar{\pi})^{\beta} & \pi>\bar{\pi}
\end{array}\right.
$$

Where $\pi$ denotes the inflation rate, $\varnothing \in[0,1]$ represents the weight given to the deflation loss by economic representatives, and risk aversion coefficients $\alpha$ and $\beta$ stand for different risk tolerance about inflation and deflation respectively.

Based on this, deflation risk and the risk of excessive inflation can be defined as 


$$
\begin{array}{ll}
D R_{\alpha}=-\int_{-\infty}^{\underline{\pi}}(\underline{\pi}-\pi)^{\alpha} d F(\pi) & \alpha>0 \\
I R_{\beta}=\int_{\bar{\pi}}^{+\infty}(\pi-\bar{\pi})^{\beta} d F(\pi) & \beta>0
\end{array}
$$

Where either risk is a measurement about expected results defined on two bounds, risk-averse coefficients and the probability distribution. These two definitions identify the typical fact the economic representatives try to avoid the inflation realization falling outside the target zone.

Furthermore, when $\alpha=\beta=0$, the risk measurement degenerates to the probability the real inflation deviates from the target zone; when $\alpha=\beta=1$, DR1 becomes the measurement of expected deflation whereas IR1 becomes the measurement of expected excess inflation; when $\alpha=\beta=2$, risk measurements turns into the target semi-variance.

In addition, discussions about inflation risk actually concern the trade-off between upside risk corresponding to inflation and downside risk corresponding to deflation. The balance of risks, which is the weighted average of DR and IR, provides a flexible tool to analyze the price level stability. A positive balance of risk means the emergence of inflation risk, and meanwhile a negative one implies the existence of deflation risk.

\section{THE CALCULATION OF INFLATION RISK}

Let $\pi_{\tau}, \tau=1,2, \ldots, T$ represents inflation observation, $\Omega_{\tau}$ represents the information set up to time $r, h_{t+1}$ represents the conditional variance of inflation, $x_{k, \tau}, k=1, \ldots, s$ represents the other external influential variables. Assuming that inflation dynamic can be described by an $A R-G A R C H$ model, the conditional mean $\mu_{t+1}$ follows a $A R(p)$ process,

$$
\mu_{\tau+1}=\varphi_{0}+\sum_{i=1}^{p} \varphi_{i} \pi_{\tau-i+1}+\sum_{k=1}^{s} \sum_{j=1}^{q_{k}} \varphi_{k, j} X_{k, \tau-j+1}
$$

The variance follows a $\operatorname{GARCH}(1,1)$ process,

$$
\begin{aligned}
& \pi_{\tau+1}=\mu_{\tau+1}+u_{\tau+1}, \quad u_{\tau+1}=\varepsilon_{\tau+1} \sqrt{h_{\tau+1}}, \quad \varepsilon_{\tau+1} \mid \Omega_{\tau} \sim \text { i.i.d. }(0,1) \\
& h_{\tau+1}=\theta_{0}+\theta_{1} u_{\tau}^{2}+\theta_{2} h_{\tau}
\end{aligned}
$$

The measurement about inflation and deflation risks can be obtained through Bootstrap approach.

Taking inflation risk $I R_{\beta, \tau+1}(\bar{\pi})=\int_{\bar{\pi}}^{+\infty}\left(\pi_{\tau+1}-\bar{\pi}\right)^{\beta} d F\left(\pi_{\tau+1}\right)$ as an example, the estimated standardized residual can be expressed as $\hat{\varepsilon}_{\tau+1}=\left(\pi_{\tau+1}-\hat{\mu}_{\tau+1}\right) /\left(\hat{h}_{\tau+1}\right)^{1 / 2}$. Given the empirical distribution of $\hat{\varepsilon}_{\tau+1}$ and the estimation about equation (4), the predicted density can be obtained based on the bootstrap sampling about $\left\{\pi_{\tau+1}^{r}\right\}$.

Thus, inflation risk can be calculated as

$$
I R_{\beta, \tau+1}(\bar{\pi})=\operatorname{Pr}\left(\pi_{\tau+1}^{r}>\bar{\pi}\right) E\left[\left(\pi_{\tau+1}^{r}-\bar{\pi}\right)^{\beta} \mid \pi_{t+1}^{r}>\bar{\pi}\right]
$$

Where the probability $\operatorname{Pr}\left(\pi_{\tau+1}^{r}>\bar{\pi}\right)$ can be obtained through calculating the proportion of $\left(\pi_{\tau+1}^{r}-\hat{\mu}_{\tau+1}\right) / \sqrt{\hat{h}_{\tau+1}}$ exceeding $\left(\bar{\pi}-\hat{\mu}_{\tau+1}\right) / \sqrt{\hat{h}_{\tau+1}}$, and the expectation $E\left[\left(\pi_{\tau+1}^{r}-\bar{\pi}\right)^{\beta} \mid \pi_{\tau+1}^{r}>\bar{\pi}\right]$ can be estimated by the sample moment
$\frac{1}{\#\left(\pi_{\tau+1}^{r}>\bar{\pi}\right)} \sum_{\pi_{\tau+1}^{r}>\bar{\pi}}\left(\pi_{\tau+1}^{r}-\bar{\pi}\right)^{\beta}$.

\section{EMPIRICAL ANALYSIS}

\section{A. Quantifying inflation risk}

Although central banks usually choose to use the Consumer Price Index as the monitoring objectives of monetary policy making, it is essentially not a very thorough representative about price level. Comparatively speaking, GDP deflator is a more effective delegation about price level. Thus, in this article, we choose quarterly GDP deflator change compared to that in the last year to calculate quarterly inflation rate. Considering inflation is better a monetary phenomenon, thus we add the growth of broad money $\Delta \mathrm{M} 2$ as a control variable like Lu et al. (2016) do. [3]

When calculating the risk of price instability, the determination of target inflation area plays a key role and influences the judgment about risk magnitude. Consulting the calculation about GDP deflator threshold in Liu (2009), [4] we set the target inflation zone to [5\%,6\%] and quantify the risk of price instability under the circumstance of $\alpha=\beta=2$. All risk values are shown in "Fig. 1".

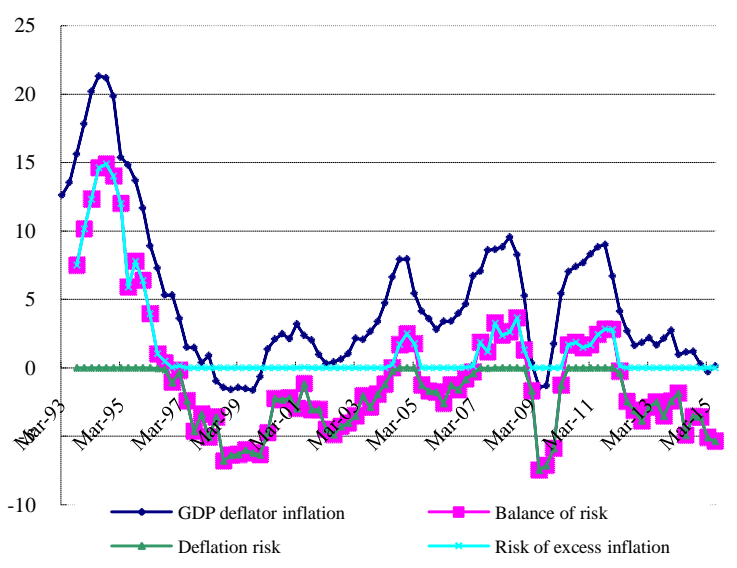

Fig. 1. GDP deflator inflation rate and inflation risk

"Fig. 1" illustrates that the balance of risk reflects the inflation dynamics well. From the comparison of risk magnitude, deflation risks between Quarter II and Quarter IV, 2009 are as big as those between Quarter III, 1998 and Quarter IV , 1999. From the dynamic of inflation risk, deflation risk seems more severe than the expected before. In the short run, along with the increasing economic downturn pressure, price level begins continues decline. Domestic deflation risk shows some continuing trend and short-term deflation pressure is noteworthy. 


\section{B. Price instability risk and inhabitant perception}

Generally speaking, inflation risk fluctuation reflects price instability and higher or lower risk value means more severe deviation of real price level from desirable zone. As a rational consumer, the perception about price level is supposed to vary with the fluctuation of price level deviation. In order to figure out the relation between inflation risk and consumer perception, we build the estimation model based on the calculated risk values and The Report on Questionnaire for Depositors in Cities and Towns lead by the Peoples' Bank of China.

The Questionnaire for Depositors in Cities and Towns is a quarterly investigation set up by the Peoples' Bank of China (PBoC) since 1999. In every quarter, PBoC randomly picks up 50 depositors from each branch of 400 banks covering nationwide 50 cities, 20 thousand depositors in total, as objectives of investigation. The content of investigation includes four aspects: judgment about economic operation, status about deposits and liabilities, consumption status, fundamental state for depositors. All indexes in the report adopt the diffusion index calculating method and fluctuate in the range of $[0,100 \%]$. A value above $50 \%$ reflects the expanding trend of this index while a value below $50 \%$ illustrates that the index tends to go bad.

We respectively use four different indexes, current revenue feeling index, future revenue confidence index, current price satisfaction index, and future price expectation index, as the dependent variable and build the regression model taking balance of risk as independent variable, and real output as control variable, to explore the nexus between price instability risk and consumer perception "Fig. 2".

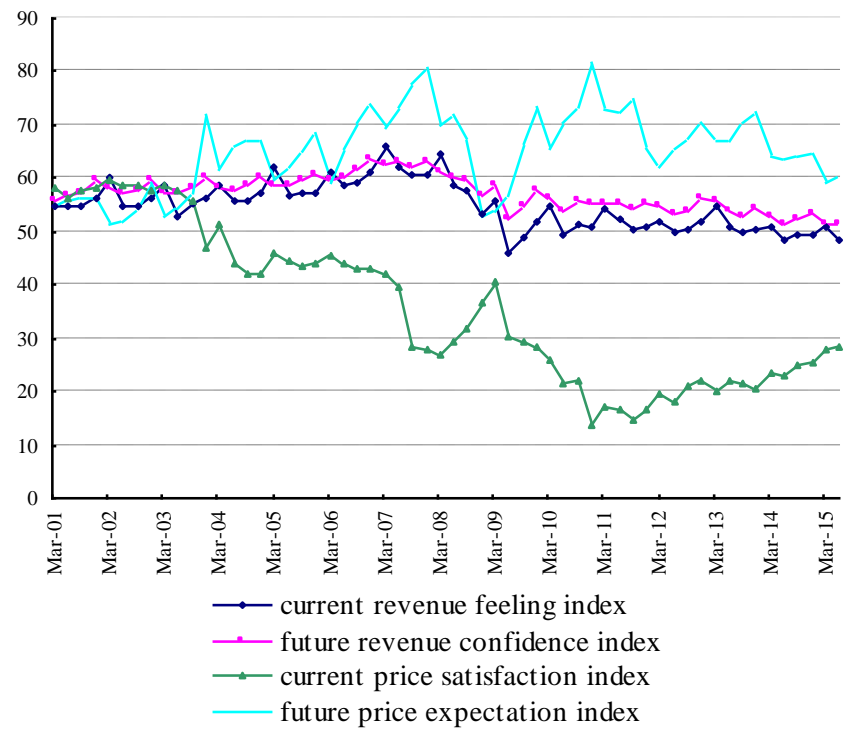

Fig. 2. Inhabitants' perception

Analyzing from 3rd Quarterly Report on the Questionnaire for Depositors in Cities and Towns, the current price satisfaction index is $27.8 \%$, decreasing 0.6 percentage point compared with last quarter. $48 \%$ inhabitants think "the price is too high to accept" increasing 0.6 percentage point compared with last quarter. The future price expectation index is $63.5 \%$, rising 3.1 percentage point compared with last quarter. $31.3 \%$ residents believe the price level will ascend while $50.2 \%$ residents think it will keep stable. Except $11.2 \%$ residents express the view that it is uncertain, only $7.3 \%$ residents expect the price to go down.

Moreover, the current revenue feeling index is $47.3 \%$, declining 1.2 percentage point compared with last quarter. $80.7 \%$ residents think the revenue will increase or basically keep invariant, decreasing 1.8 percentage point compared with last quarter. The future revenue confidence index is $50.1 \%$, dropping 1.4 percentage point compared with last quarter.

In order to enhance the explanation capacity, we add some lags of explained variable and employ Stepwise Least Squares to ascertain the optimal model. All results are illustrated in "Table I".

TABLE I. REGRESSION OF INHABITANTS' PERCEPTION ON BALANCE OF RISK

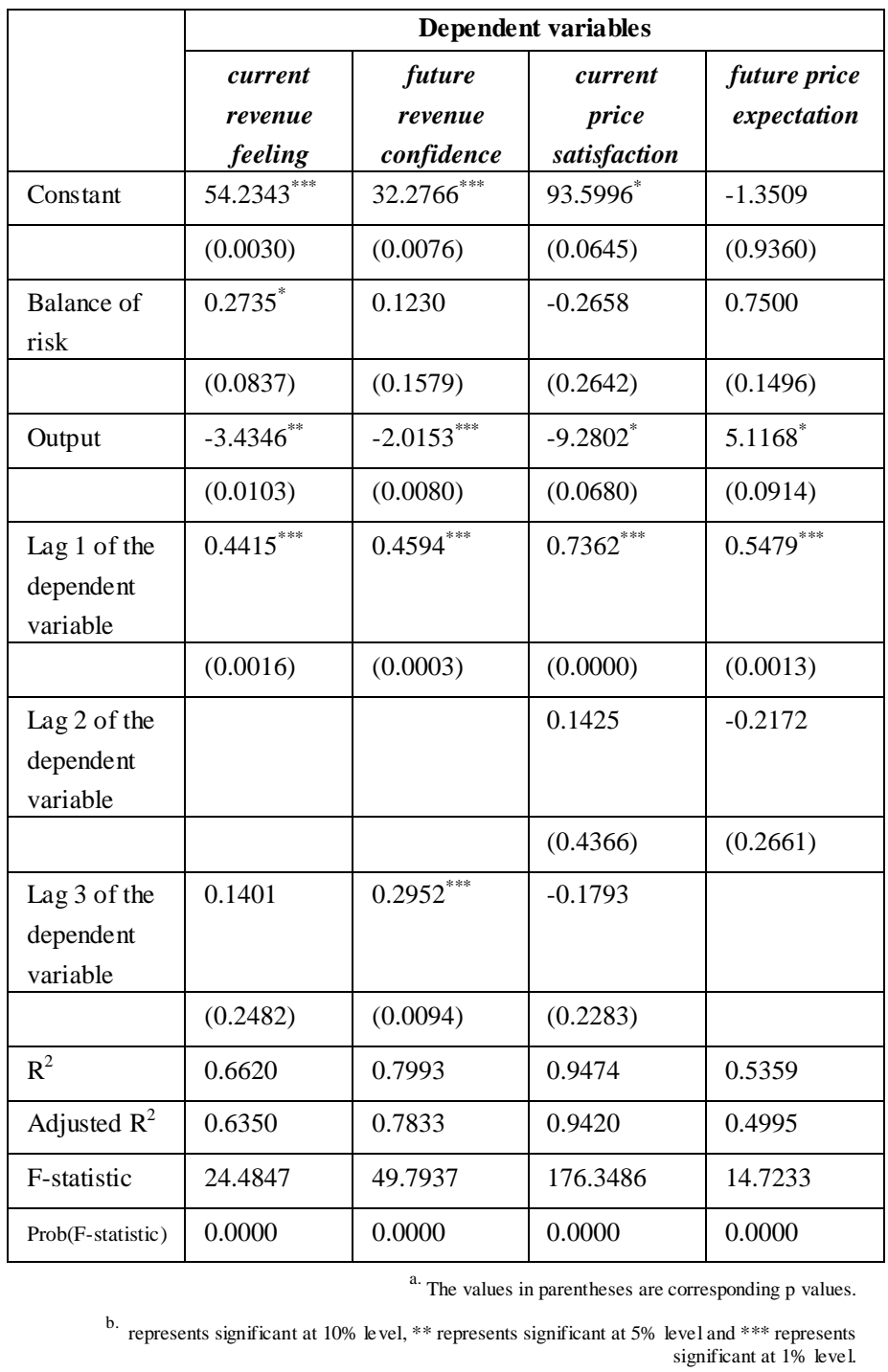

Empirical results seem to validate a very weak link between price instability risk and consumer perception. The coefficient 
of balance of risk is significant only in the model with the current revenue feeling index as dependent variable at $10 \%$ significant level, which shows that balance of risk barely has notable influence on consumer perception. As for the sign and magnitude of the significant coefficient, on one hand, price instability risk is positively linked with inhabitants' current revenue feeling which means higher price level deviation stimulates inhabitants' happiness about current revenue; on the other hand, the price instability risk has a relatively faintish impact on consumer perception.

\section{SUMMARY}

During the development of macroeconomic, price stability is usually abnormal while its instability often shows up. Price instability risk influences various aspects of macroeconomic research. However, due to lack of effective measuring mechanism, research on the nexus between inflation/deflation risk and other important economic activities, stands in silence for a long while. Quantifying price instability risk opens a new window for modern macroeconomic research. This article makes an empirical analysis on the relation between price instability risk and consumer perception and contributes to the literature in the strands of inflation empirical analysis.

\section{ACKNOWLEDGMENT}

The authors are grateful to the financial supports from the Ministry of Education Humanities and Social Science Research Youth Fund (15YJC790086); China Postdoctoral Science Foundation (2015T80276); Science Foundation for Young Teachers of Northeast Normal University (14QNJJ039); Jilin Social Science Foundation (2014B40); and Jilin Scientific and Technology Development Plan (20150418048FG).

\section{REFERENCES}

[1] Machina M. J., and M. Rothschild, "Risk", in The New Palgrave Dictionary of Economics, edited by J. Eatwell, M. Millgate, and P. Newman, 1987, pp. 203-205.

[2] Lutz Kilian, and Simone Manganelli, "Quantifying the Risk of Deflation", Journal of Money, Credit and Banking, 2007, Vol. 39, pp. 521-590.

[3] Y.Q. Liu, "The Logic and Method on Macroeconomic Analysis of Chinese Economy", Economic Research Journal, 2009, Issue 9, pp. 15$26+38$.

[4] C. Lu, K. Shi, Y.F. Cai, and L. Nie, "Quantifying China's Deflation Risk and the Choice of Monetary Policy Tools against Deflation", Journal of Northeast Normal University, in press. 